\title{
Conceptual developments of aryldiazonium salts as modifiers for gold colloids and surfaces
}

\author{
Ahmad A. L. Ahmad, ${ }^{1}$ Javad Basil Marutheri Parambath, ${ }^{2}$ Pavel S. Postnikov, ${ }^{3}$ Olga \\ Guselnikova, ${ }^{3}$ Mohamed Mehdi Chehimi, ${ }^{4}$ Mitchell R. M. Bruce, ${ }^{1}$ Alice E. Bruce, ${ }^{1, *}$ Ahmed A. \\ Mohamed $^{2, *}$ \\ 1. Department of Chemistry, University of Maine, Orono 04469, Maine, USA \\ 2. Department of Chemistry, College of Sciences, University of Sharjah, Sharjah 27272, UAE \\ 3. Research School of Chemistry \& Applied Biomedical Sciences, Tomsk Polytechnic \\ University, Tomsk 634050, Russian Federation \\ 4. Université de Paris, CNRS-UMR 7086, Interfaces, Traitements, Organisation et DYnamique \\ des Systèmes (ITODYS), F-75013 Paris, France
}


ABSTRACT: Modified colloids and flat surfaces occupy an important place in materials science research due to their widespread applications. Interest in development of modifiers that adhere strongly to surfaces relates to the need for stability under ambient conditions in many applications. In the last 20 years, diazonium salts have evolved as the primary choice for modification of surfaces. The term 'diazonics' has been introduced in the literature to describe "the science and technology of aryldiazonium salt-derived materials". The facile reduction of diazonium salts via chemical or electrochemical processes, irradiation stimuli, or spontaneously, results in efficient modification of gold surfaces. Robust gold-organic nanoparticles and films modified by using diazonium salts are critical in electronics, sensors, medical implants, and materials for power sources. Experimental and theoretical studies suggest that gold-carbon interactions constructed via chemical reactions with diazonium salts are stronger than nondiazonium surface modifiers. This invited feature article summarizes the conceptual development of recent studies of diazonium salts in our laboratories and others with a focus on surface modification of gold nanostructures and flat surfaces, and their applications in nanomedicine engineering, sensors, energy, forensic science, and catalysis.

Keywords. Diazonics, diazonium salts, gold-carbon nanoparticles, applications, robust modifiers. 


\section{INTRODUCTION}

Contemporary surface modifiers have transformed grafting research methodologies from academic interest to industrial and medicinal applications. ${ }^{1-10}$ Jean Pinson and co-workers were the first to report the mechanism of a reductive strategy and the strong binding of aryl groups on glassy carbon electrodes. ${ }^{4}$ Surface modification by organic functional groups, which formed covalent bonds with the surface established the use of aryldiazonium salts as coupling agents and surface modifiers in materials science research. ${ }^{11-14}$ Aryldiazonium salts are superior alternatives to thiols in the design of nanoparticles and surface modification due to their higher stability. For example, thiols suffer thermal degradation. ${ }^{15}$

Abundant routes for the activation of diazonium salts have been described such as photoreduction, sonication, electroless, electrochemical, chemical, and green methods. ${ }^{16-18}$ As far as the typical surfaces which have undergone surface modification, they include semiconductors, allotropes of carbon, biomedical implants such as steel and flexible plastics, metals from all groups in the periodic table, metal oxides, flexible indium tin oxide substrates, and agricultural wastes. $^{14,19-23}$ Aryldiazonium salts are good coupling agents for polymers, biomacromolecules, and adherent coatings in chemical, biological, and optical sensing purposes. ${ }^{14}$ In the immobilization of metal nanoparticles, aryldiazonium salts are used in the modifications of nanomaterials to provide specialty fillers for polymers, ${ }^{6}$ enhance the performance of sensing layers, ${ }^{19,24}$ and tune optical properties. ${ }^{7,8}$

In contrast to the aforementioned statement regarding the successful modification of many metals, diazonium precursors form unstable organic layers with early transition metals such as vanadium. ${ }^{25}$ Moreover, surface modification across the periodic table results in various linkers 
such as M-O-C and M-N=N-C. ${ }^{14,25,26}$ Mesnage, et al. reported a detailed study of the spontaneous grafting of aryldiazonium salts on nickel and gold surfaces. ${ }^{21}$ The grafting mechanism was studied via mechanical anchoring, heterolytic, or homolytic dediazoniation using XPS and IR of the film coating the metal surfaces. The proposed mechanism for the growth of the organic film on the gold surface is reproduced in Scheme $1 .^{21}$

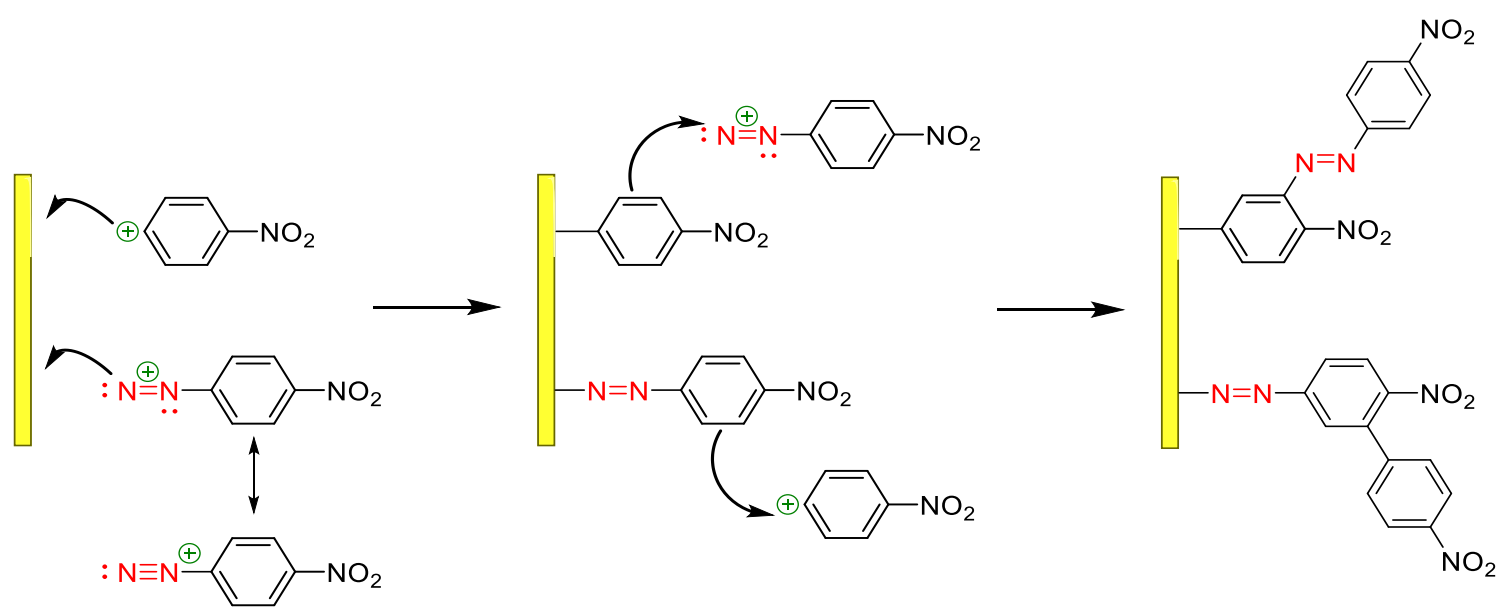

Scheme 1. Proposed mechanism for the spontaneous grafting of aryldiazonium salts on a gold substrate. Reproduced from ref 21. Copyright 2012, American Chemical Society.

Tetrachloroaurate(III) counterions are excellent stabilizers for aryldiazonium cations. ${ }^{17,26-30}$ The preparation of aryldiazonium gold(III) salts is carried out in the presence of tetrachloroauric acid, $\mathrm{HAuCl}_{4}$, which provides an acidic medium for the diazotization reaction and also promotes complete dissolution of the aniline precursors to yield ammonium salts. Mohamed, et al. protonated 4-aminobenzonitrile with $\mathrm{HAuCl}_{4}$ in acetonitrile to form the ammonium benzonitrile tetrachloroaurate(III), which was subsequently oxidized using nitrosyl cation to form the diazonium gold(III) salt. ${ }^{17}$ The synthesis of the salts $\left[\mathrm{X}-4-\mathrm{C}_{6} \mathrm{H}_{4} \mathrm{~N} \equiv \mathrm{N}\right] \mathrm{AuCl}_{4}(\mathrm{X}=\mathrm{F}, \mathrm{Cl}, \mathrm{Br}, \mathrm{I}$, $\mathrm{CN}, \mathrm{NO}_{2}$ ) was also carried out by the oxidation of anilines using sodium nitrite in mineral acid followed by counterion exchange with tetrachloroaurate, $\left[\mathrm{AuCl}_{4}\right]^{-}$in water. ${ }^{27}$ The aryldiazonium 
salts are used in the construction of robust gold-carbon nanoparticles and the mechanism of their formation is shown in equations $1-3 .^{27}$

$$
\begin{aligned}
& {\left[\mathrm{X}-4-\mathrm{C}_{6} \mathrm{H}_{4} \mathrm{~N} \equiv \mathrm{N}\right]^{+}+\mathrm{e}^{-} \rightarrow \mathrm{Ar}^{-}+\mathrm{N}_{2}} \\
& {\left[\mathrm{AuCl}_{4}\right]^{-}+3 \mathrm{e}^{-} \rightarrow \mathrm{Au}(0)+4 \mathrm{Cl}^{-}} \\
& \mathrm{nAu}(0)+\mathrm{mAr}^{\cdot} \rightarrow \mathrm{Au}_{\mathrm{n}}(\mathrm{Ar})_{\mathrm{m}}
\end{aligned}
$$

The term 'diazonics' was introduced in the literature in 2015 to describe "the science and technology of aryldiazonium salt-derived materials". ${ }^{14}$ We are entering the fourth decade of diazonics if we consider that time zero corresponds to the seminal work on diazonium surface chemistry of Jean Pinson. ${ }^{4,14}$ The realization of the occurrence of robust interfacial surface-aryl bonds has raised interest among surface and material scientists. Many types of materials have been subjected to diazonium modifications, and data from research laboratories around the world have been compiled in review papers and book chapters. ${ }^{1,9,10}$

The focus of this feature article is on the conceptual development of diazonium salts as surface modifiers for gold nanoparticles and flat surfaces, and their applications in forensics, nanomedicine engineering, sensors, energy, and catalysis. We discuss the efficient use of aryldiazonium salts for the generation of aryl-capped gold nanoparticles and flat gold surfaces.

\section{PROBING THE BONDING AND STRUCTURES OF GRAFTED SURFACES}

Surface science instrumentation and theoretical calculations have been used to probe the nature and bonding of organic layers with surfaces. The presence of an organic shell on a metal core can be confirmed by X-ray photoelectron spectroscopy (XPS). However, in the grafting of a gold surface, it is difficult to verify Au-C connectivity using XPS due to the similar electronegativities

of gold and carbon. ${ }^{21}$ The Au-C interfacial bond in gold-aryl nanoparticles has been probed by 
surface-enhanced Raman spectroscopy SERS and high-resolution electron energy loss spectroscopy (HREELS). ${ }^{12}$ EXAFS (extended X-ray absorption fine structure) is another powerful technique for probing the surface environment. EXAFS analysis provides a distance of 2.2-2.3 $\AA$ for the Au-C bond in alkyne surface modifiers. ${ }^{14}$ DFT calculations of an optimized model system for gold-aryl nanoparticles, $\mathrm{Au}_{38}-\mathrm{C}_{6} \mathrm{H}_{4}-\mathrm{COOH}$, show an $\mathrm{Au}-\mathrm{C}$ bond distance of $2.04 \AA$, which is related to a binding energy of $-59.2 \mathrm{kcal} / \mathrm{mol}{ }^{28}$ Various experimental observations also support the likelihood of the existence of gold-carbon bonding, such as the robustness to sonication in water and organic solvents. ${ }^{11,12,21,28}$ Additional evidence comes from the efficient blocking of electron transfer by grafting of gold-aryl thin films on the surface of a glassy carbon working electrode, which was probed electrochemically in the presence of oneelectron transfer agents such as ferrocene and ferrocyanide. ${ }^{31}$

\section{ARYLATION OF GOLD NANOPARTICLES AND NANORODS}

In 2015 we summarized the findings on the arylation of gold nanoparticles and early studies of modification of nanorods. ${ }^{14}$ Gold nanostructures were first prepared and then arylated using aryldiazonium salts via a spontaneous route in acetonitrile. The method is versatile and has been tested with several diazonium salts bearing $\mathrm{NO}_{2}$ and $\mathrm{SH}$ for the detection of $\mathrm{Hg}(\mathrm{II})$ in water, ${ }^{32}$ $\mathrm{NO}_{2}, \mathrm{CN}$ or $-\mathrm{N}\left(\mathrm{CH}_{3}\right)_{2}$ for the visual detection of arylamine (Figure 1), ${ }^{33}$ and anthraquinone in a two-phase method. ${ }^{34}$ The method has been extended to other aryldiazonium salts with possible post-functionalization. For example, Troian-Gautier et al., grafted calix[4]arene-tetradiazonium to prefabricated gold NPs. ${ }^{35}$ 


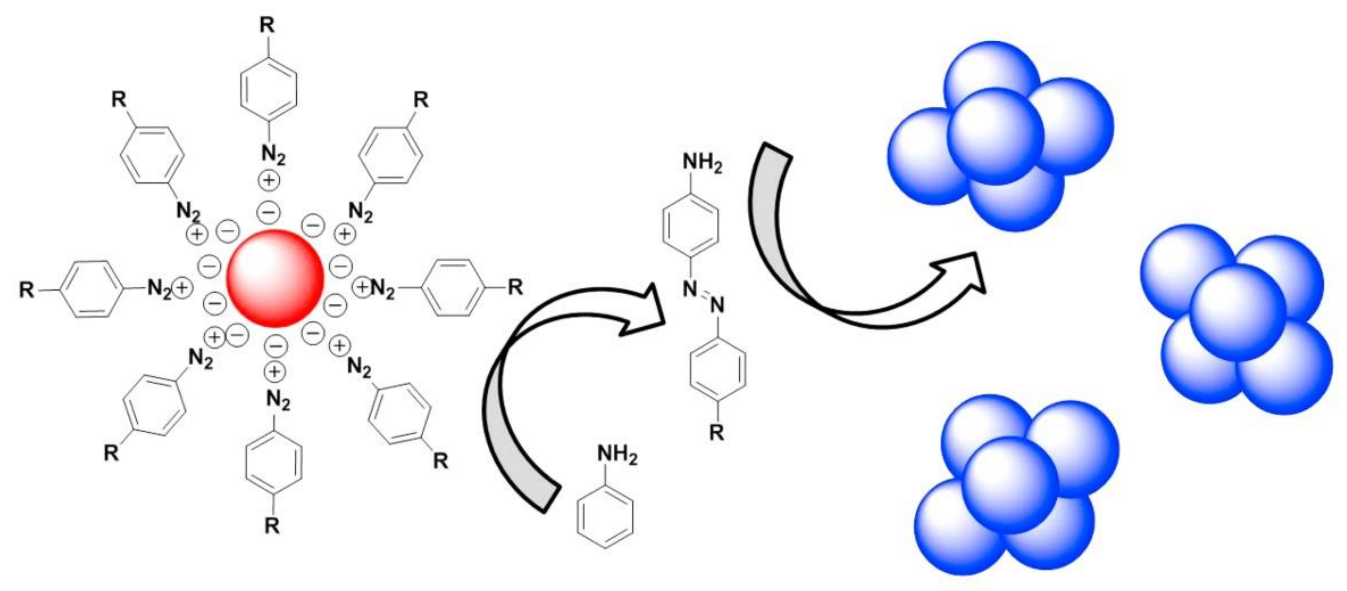

$\mathrm{R}=-\mathrm{NO}_{2}$ (DS1), $-\mathrm{CN}$ (DS2), $-\mathbf{N}\left(\mathrm{CH}_{3}\right)_{2}$ (DS3)

Figure 1. Schematic illustration of the diazonium salt-AuNPs based colorimetric system for the detection of anilines. DS1 (4-nitrobenzenediazonium), DS2 (4-cyanobenzenediazonium), and DS3 (4-(dimethylamino)benzenediazonium) Reproduced with permission from ref 33. Copyright 2017, Elsevier.

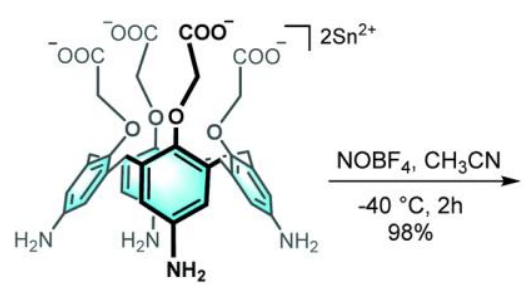

1

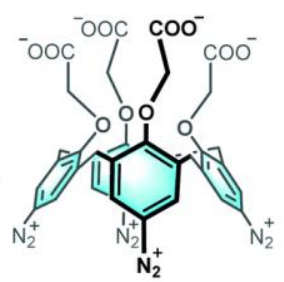

2
1) a. $\mathrm{HAuCl}_{4} \mathrm{NaBH}_{4} \mathrm{CH}_{3} \mathrm{CN}, 0^{\circ} \mathrm{C}, 2 \mathrm{~h}$

b. $15 \mathrm{~nm}$ AuNPs, $\mathrm{NaBH}_{4}, \mathrm{H}_{2} \mathrm{O}, 18 \mathrm{~h}$

c. $10 \mathrm{~nm}$ AuNPs, $\mathrm{H}_{2} \mathrm{O} / \mathrm{CH}_{3} \mathrm{CN}, 18 \mathrm{~h}$

d. $5 \mathrm{~nm}$ AuNPs, $\mathrm{H}_{2} \mathrm{O} / \mathrm{CH}_{3} \mathrm{CN}, 18 \mathrm{~h}$

2) $\mathrm{NaOH}$

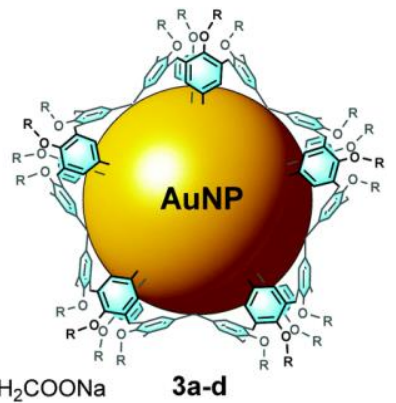

Figure 2. Synthesis of calix[4]arene-tetradiazonium salt 2 and AuNPs $3 \mathrm{a}$ from 1 and $\mathrm{HAuCl}_{4}$. AuNPs $3 b-\mathrm{d}$ by grafting 2 onto citrate-protected particles. Reproduced with permission from ref 35. Copyright 2016, Royal Society of Chemistry. 


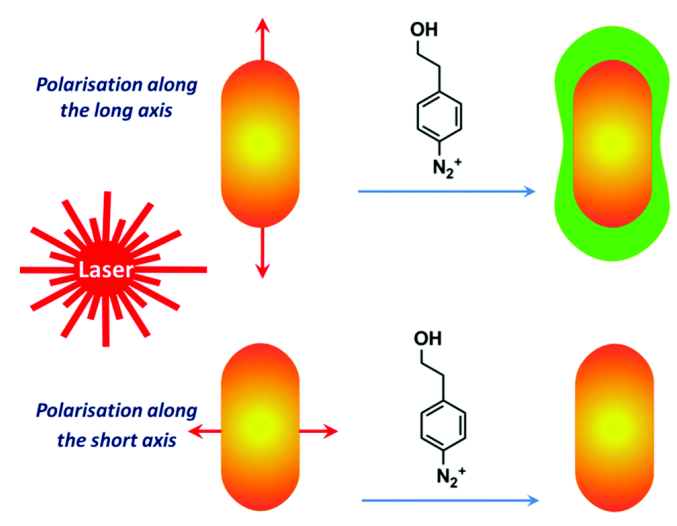

Figure 3. Regioselective surface functionalization of gold nanorods (AuNRs) under plasmon excitation with polarized light. The nanostructures were incubated for $10 \mathrm{~s}$ in an aqueous solution of hydroxyethyl phenyl diazonium salt under laser irradiation polarized along the nanorod long axis and short axis directions, respectively. Reproduced with permission from ref 36. Copyright 2017, Royal Society of Chemistry.

Gold nanorods (AuNRs) not only differ in shape but also have distinctive features due to their synthesis conditions. Under laser excitation, arylation of AuNRs is anisotropic as depicted in Figure $3 .{ }^{36}$ Regioselective surface functionalization of gold nanorods (AuNRs) under plasmon excitation with polarized light was reported. ${ }^{36}$ Under polarized light, plasmon excitation of AuNRs yields arylated AuNRs surfaces, in confined nanoscale areas, however with a distinct thickness along the length or breadth of the NRs due to maximum of the near-field intensity enhancement. The nanostructures were incubated for $10 \mathrm{~s}$ in an aqueous solution of hydroxyethyl phenyl diazonium salt under laser irradiation polarized along the nanorod long axis and short axis directions, respectively. The seed growth method using $\mathrm{AgNO}_{3}$ and cetrimonium bromide $(\mathrm{CTAB})$ is well established ${ }^{37}$ but requires controlled experimental conditions to obtain reproducible size and length-to-breadth ratio. ${ }^{38}$ It was demonstrated that AuNRs prepared via the seed growth method using silver nitrate undergo a cation exchange reaction with CTAB followed by reductive grafting, resulting in Au-C bonds at the AuNRs-aryl interface. ${ }^{39}$ However, the 
presence of silver at the AuNRs surface resulted in the simultaneous incorporation of $\mathrm{Ag}-\mathrm{C}$ bonds.

So far, we have focused on gold nanostructures that are essentially in solution. However, gold NPs can also be immobilized on surfaces and post-functionalized with aryl groups. Attachment of gold NPs on arylated ${ }^{40,41}$ or pristine electrode surfaces ${ }^{41}$ was carried out for applications in lead and copper(II) sensing, respectively. For previous and similar strategies, the reader is referred to the review by Mohamed, et al. ${ }^{14}$

\section{MODIFICATION OF FLAT GOLD SURFACES}

Diazonium modification of flat gold surfaces via an electrochemical reduction route started with the attachment of phenylene functional groups to gold wires and electrodes. However, recently the focus has shifted to the functionalization of nanometer-scale gold films, which produce unique electrical and optical properties. ${ }^{18,42-44}$ The group of Postnikov and Lyutakov developed methods of diazonium modification for the fabrication of 2D SERS and optical fiber-based surface plasmon resonance (SPR) sensors. ${ }^{45-47}$ Their comprehensive investigation on the functionalization of thin gold films of $18 \mathrm{~nm}$ using stable aryldiazonium tosylates studied the spontaneous and electrochemical modification in water with $-\mathrm{NO}_{2},-\mathrm{NH}_{2},-\mathrm{COOH}$, and $-\mathrm{C}_{8} \mathrm{~F}_{17}$ substituents (Figure 4A) ${ }^{48}$ It was concluded that depending on the substituent and activation method, diazonium salts can graft 1-10 phenylene layers. Spontaneous modification formed approximately monomolecular thick films that can be used as SPR or SERS sensors (Figure 4B) ${ }^{49}$ Electrochemical activation produced a thick polyphenylene layer on the metal surface for tunable plasmonic devices or plasmon-based lasers. ${ }^{50}$

A large body of fundamental knowledge on the modification of thin gold films by diazonics has resulted in significant progress in sensing applications. ${ }^{51,52}$ The recent reviews by Liu and 
Pinson, et al. summarize advances in the use of aryldiazonium salts for the modification of sensors and biosensors. ${ }^{24,51}$ Several studies report the use of thin gold films for the design of sensing devices for SERS spectroscopy ${ }^{53-57}$ As a transducer of analytical signal, excimer laserinduced gratings coated by $20 \mathrm{~nm}$ gold film were utilized for the realization of a high plasmonsupported area of $2 \times 1 \mathrm{~cm}^{57}$
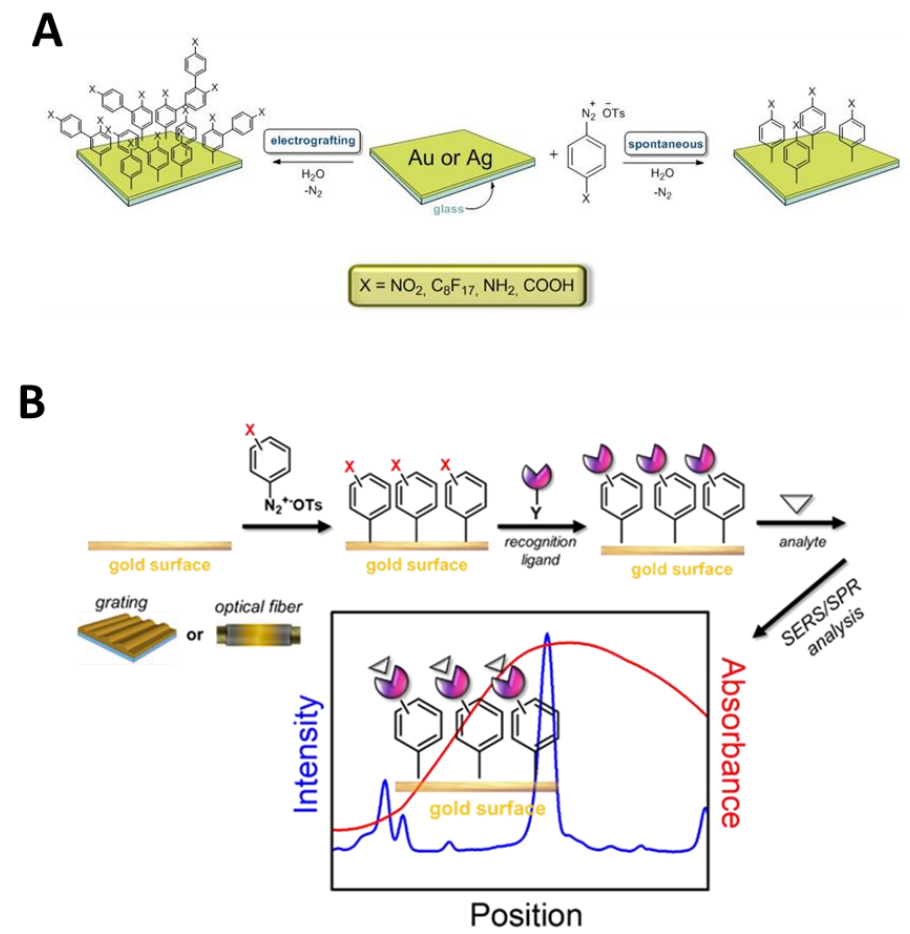

Figure 4. (A) Schematic representation of the proposed covalent modification of plasmon-active metal surface. Reproduced from ref 48. Copyright 2019, Elsevier. (B) Sensor preparation based on diazonium modification of gold surfaces (gratings or optical fibers) followed by grafting of recognition ligands for SPR (based on shift in the visible spectrum) and SERS (changes in Raman signal).

Diazonics have enabled high loading/surface coverage of functional groups on the gold surface of plasmon-active thin films, ${ }^{58,59}$ which is considered a perfect model for the study of plasmoninduced chemical transformations using operando spectroscopy (Figure 5a-c). Utilizing these advantages, 4-ethynylphenyl grafted to a gold-coated grating via diazonium chemistry 
demonstrates selective reduction to double $^{60}$ and single bonds (Figure 5a), plasmon polymerization (Figure $5 b$ ), and cycloaddition of azides (Figure $5 \mathrm{c}$ ). ${ }^{56-63}$

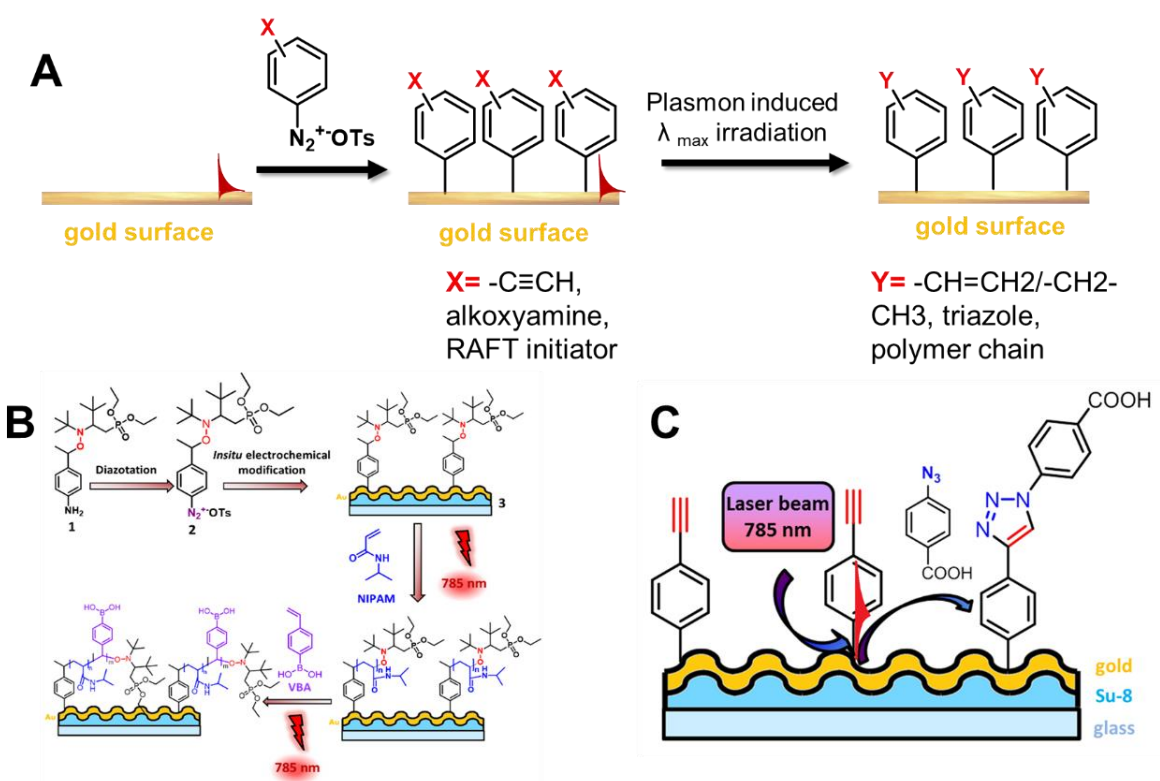

Figure 5. (A) Plasmon-induced chemistry on gold surfaces. (B) Preparation of poly(4-vinyl boronic acid)/poly(N-isopropylacrylamide (PVBA/PNIPAM) block copolymers on the surface of gold grating via plasmon polymerization. Reproduced with permission from ref 56. Copyright 2019, Royal Society of Chemistry. (C) Plasmon-induced cycloaddition of 4-carboxyphenylazide to 4-ethynylphenyl groups. Reproduced from ref 62. Copyright 2019, American Chemical Society.

\section{PREPARATION OF GOLD-CARBON NANOPARTICLES FROM ARYLDIAZONIUM GOLD SALTS USING PHYSICAL METHODS}

Gold-carbon nanoparticles are synthesized from aryldiazonium gold(III) salts using various routes including chemical, spontaneous, electrochemical, and femtosecond laser ablation. ${ }^{64-67}$ Two interesting routes are discussed here, namely electrochemical reduction in water in the presence of polyaniline (PANI) ${ }^{64}$ and the femtosecond laser ablation of the salts in acetonitrile. ${ }^{65}$ We have shown that electrochemical reduction of diazonium gold(III) salts in the presence of PANI at different potential values produce PANI-AuNPs nanocomposites. Laser irradiation in liquids is a well-discussed technique in the synthesis of metal nanoparticles. ${ }^{68,69}$ Femtosecond 
laser ablation was used for the fabrication of gold-aryl nanoparticles from diazonium salts in acetonitrile, and the gold(0) oxidation state was confirmed by XPS. ${ }^{65}$ It was also noted in TEM analysis that the size of the nanoparticles is dependent on the irradiation time; longer irradiation time results in smaller sizes. It is hypothesized that solvated electrons and hydrogen radicals generated in solution play a role in the reduction.

\section{PREPARATION OF ALLOY AND CORE-SHELL NANOSTRUCTURES}

In an extension of our interest in diazonium chemistry, we have synthesized surface-modified gold-silver alloy nanoparticles for potential applications in nanomedicine engineering. ${ }^{70}$ The nanoparticles are synthesized via three different methods: immobilization of pre-formed gold nanoparticles over silver nanoparticles; chemical co-reduction of silver nitrate in the presence of the aryldiazonium gold(III) salt, and seeding by the chemical reduction of silver nitrate in the presence of gold nanoparticles (Figure 6A). The resulting gold-silver alloy nanostructures are highly effective as antibacterial agents. The presence of gold nanoparticles has a major effect on controlling silver ion oxidative leaching and the on-demand release of silver ions for antibacterial function. ${ }^{71,72}$ 
(A)

(a)
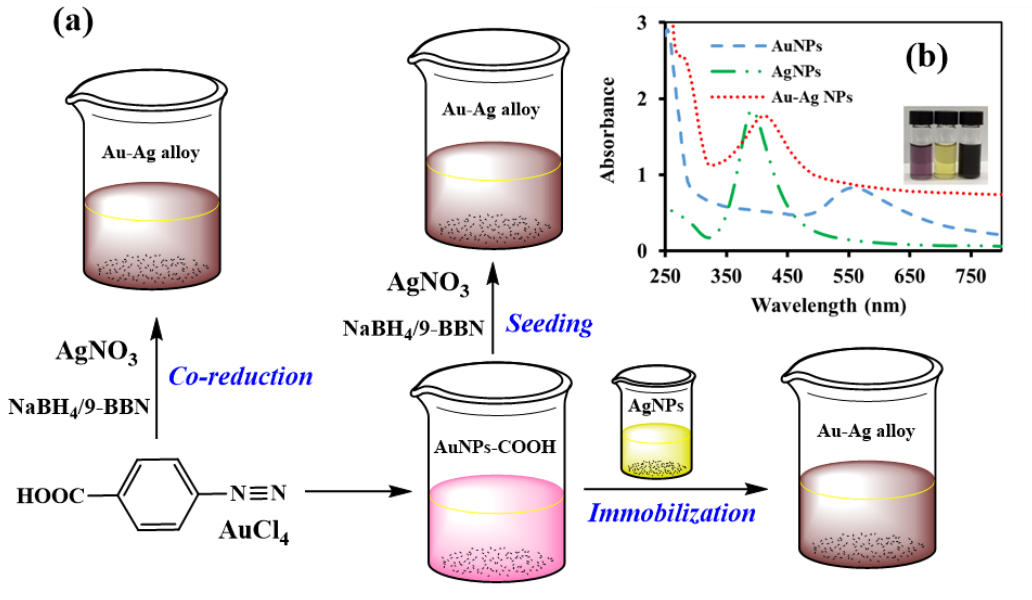

(B)

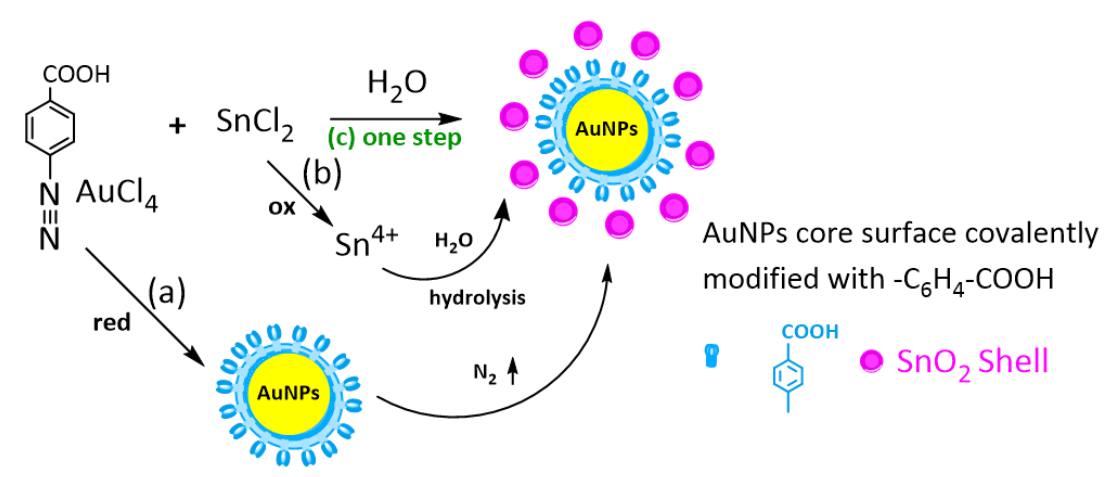

Figure 6. (A) Scheme showing the different routes for the synthesis of gold-silver alloy nanostructures, (b) UV-visible spectra of parent AuNPs and AgNPs and bimetallic Au-Ag alloys. Conditions: AuNPs formed by the reduction of aryldiazonium gold(III) salt with $0.1 \mathrm{M} \mathrm{NaBH}_{4}$; AgNPs synthesized by adding $\mathrm{AgNO}_{3}$ in $\mathrm{NaBH}_{4}$ solution; and $\mathrm{AgNO}_{3}$ reduced in the solution of pre-synthesized AuNPs using $0.1 \mathrm{M} \mathrm{NaBH}_{4}$ to form alloy nanostructures of $\mathrm{Au}-\mathrm{Ag}$. Reproduced from ref 70. Copyright 2020, Elsevier. (B) Schematic representation of the $\mathrm{Au} @ \mathrm{SnO}_{2}$ formation (a) diazonium gold salt reduction to form AuNPs functionalized with $-\mathrm{C}_{6} \mathrm{H}_{4} \mathrm{COOH}$. It is assumed that the reaction proceeded by the formation of an aryl radical followed by the formation of gold NPs. Both moieties recombine to form the organometallic gold-aryl nanoparticles, (b) oxidation of $\mathrm{Sn}^{2+}$ to $\mathrm{Sn}^{4+}$ followed by hydrolysis to $\mathrm{SnO}_{2}$, (c) total redox reaction in water which formed the core-shell nanostructure. Reproduced with permission from ref 75. Copyright 2021, Elsevier.

Core-shell nanostructures are synthesized under harsh conditions such as hydrothermal decomposition, solvothermal, microwave treatment, annealing, reflux, and chemical reagents. ${ }^{73,74}$ The low reduction potential of aryldiazonium gold(III) salts has been utilized in the fabrication of core-shell nanostructures. ${ }^{75}$ Very recently $\mathrm{Au} @ \mathrm{SnO}_{2}$ nanostructures were synthesized in water 
by a one-step green reduction of the aryldiazonium gold(III) salt with $\mathrm{SnCl}_{2} \cdot 2 \mathrm{H}_{2} \mathrm{O}$ (Figure $6 \mathrm{~B}$ ). ${ }^{75}$ The facile redox couples for $\mathrm{Au}(\mathrm{III}) / \mathrm{Au}(0)$ and $\mathrm{Sn}(\mathrm{II}) / \mathrm{Sn}(\mathrm{IV})$ generated in situ are pivotal for this spontaneous reaction, Equations 4-7. Gold(III) from the aryldiazonium gold salt is reduced to gold(0) and simultaneously $\mathrm{Sn}(\mathrm{II})$ is oxidized to $\mathrm{Sn}(\mathrm{IV})$ by $\mathrm{Au}(\mathrm{III}) /$ dissolved oxygen, and slowly hydrolyzed to the Lewis acid $\mathrm{SnO}_{2}$ shell.

$$
\begin{array}{ll}
2 \mathrm{Au}^{3+}+3 \mathrm{Sn}^{2+} & \rightarrow 2 \mathrm{Au}^{0}+3 \mathrm{SnO}_{2} \\
\text { Aryldiazoinum-AuCl} & \rightarrow \text { AuNPs }+ \text { aryl radical } \\
\text { AuNPs }+ \text { aryl radical } & \rightarrow \text { AuNPs-aryl } \\
\mathrm{Sn}^{4+}+2 \mathrm{H}_{2} \mathrm{O} & \rightarrow \mathrm{SnO}_{2}+4 \mathrm{H}^{+}
\end{array}
$$

\section{FORENSIC APPLICATIONS}

Aryldiazonium salts have been used as visualizing agents for the detection of explosives, illicit drugs, and biological fluids at crime scenes. ${ }^{76-78}$ Forensic science has begun to embrace metalaryl surface modifiers due to their high stability. ${ }^{79,80}$ The low reduction potential of aryldiazonium gold(III) salts is of greater practicality at crime scenes where metal articles may include copper, aluminum, lead, and nickel sheets and coins. The redox-based detection of latent fingerprints has emerged as a significant application of aryldiazonium gold(III) salts in forensic applications due to the spontaneous reductive formation of a gold-aryl film. ${ }^{79,80}$

Early studies of aryldiazonium gold(III) salts in forensic science in our laboratory involved imaging techniques to visualize the gold-aryl film developed on the latent fingerprint ridges. ${ }^{79}$ It is possible to capture secondary and tertiary details with considerable clarity on a copper surface, however, those captured on aluminum and lead were unclear. Highly reducing metal surfaces such as aluminum may interact with the naturally reducing fluid constituents in fingerprints leading to the very rapid reduction of the aryldiazonium salts. This explains the rapid 
development of surfaces in the first few seconds, degraded contrast, and overflow of the trenches.

(A)

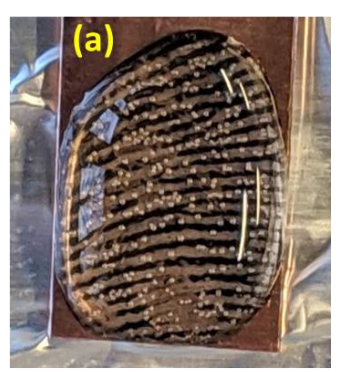

(B)

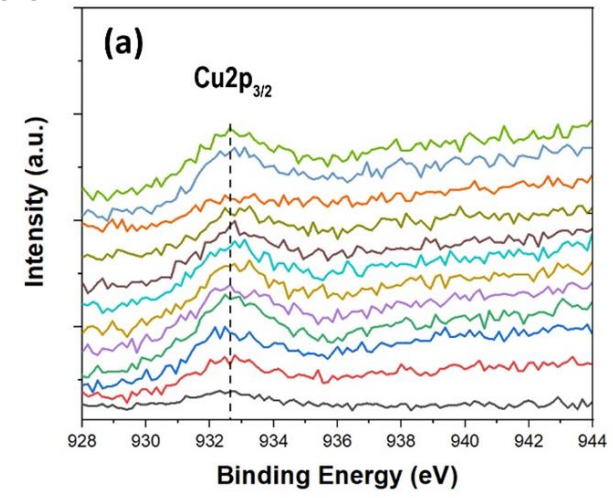

(b)
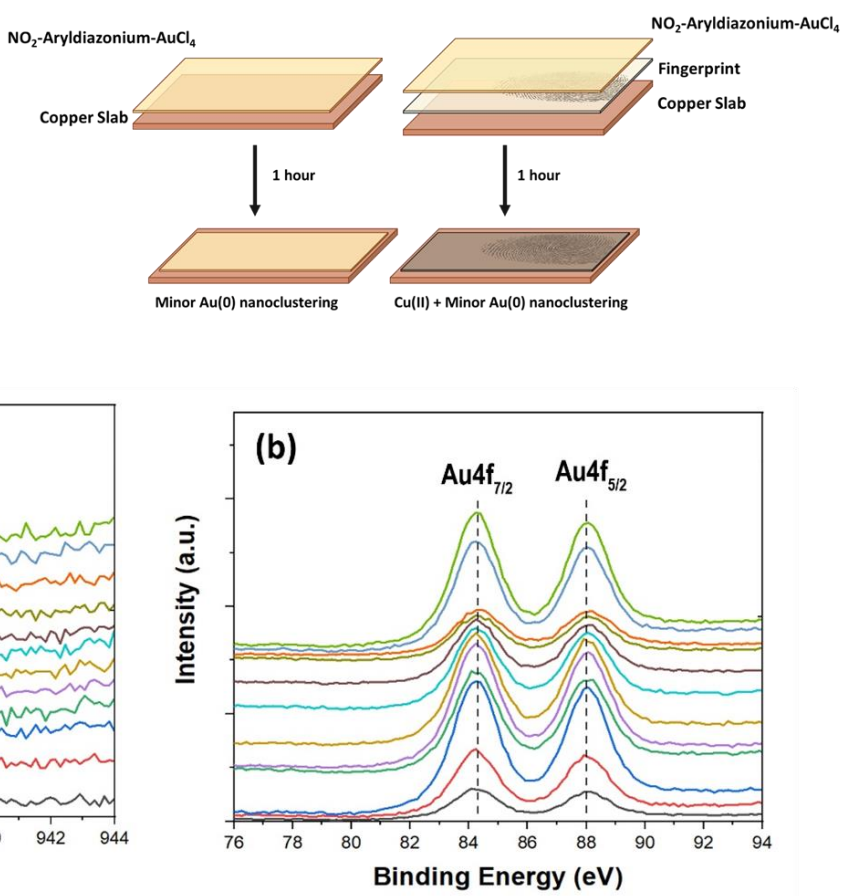

Figure 7. (A) Latent fingerprints development on copper surface. (a) Latent fingerprint development using diazonium solution on a copper sheet. Bubbles correspond to the release of nitrogen gas due to the spontaneous reduction of diazonium salt. (b) Reaction of clean and fingerprint-coated copper samples with nitrobenzenediazonium tetrachloroaurate(III) aqueous solution. (B) XPS investigation of developed fingerprints. (a) High-resolution $\mathrm{Cu} 2 \mathrm{p}$, (b) Au4f spectra of fingerprint and $\left[\mathrm{NO}_{2}-4-\mathrm{C}_{6} \mathrm{H}_{4} \mathrm{~N} \equiv \mathrm{N}\right] \mathrm{AuCl}_{4}$ treated copper coin on 12 different areas. Reproduced from ref 80. Copyright 2020, American Chemical Society.

We expanded our studies on aryldiazonium tetrachloroaurate(III) salts to utilize XPS for the quantification of the gold deposits and organic films developed on copper sheets and coins (Figure 7). ${ }^{80}$ Surprisingly, we observed the formation of copper oxide, which was diffused throughout the reduced film. Thus far, preliminary results demonstrate a proof of concept for the use of diazonium salts stabilized with gold(III) in the redox reaction for fingerprint development. 


\section{DIAZONICS IN NANOMEDICINE ENGINEERING}

Immobilization of proteins, drugs, and DNA on gold nanoparticles results in stabilization of the biomolecules and allows for effective drug delivery. ${ }^{81-83}$ The water-soluble bioconjugates synthesized using diazonics have contributed significantly to development of nanomedicine engineering. ${ }^{66,67,70,84,85}$ The bonding between the gold core and aryl shell appears to be robust in biological fluids. ${ }^{28,66,67,85}$ Carboxyl-modified gold NPs were successfully implemented in the in vitro delivery of insulin and inhibition of insulin fibrillation. ${ }^{84}$ Figure $8 \mathrm{~A}$ shows the defibrillation study of insulin fibers in the presence of gold-aryl nanoparticles. The resistance of insulin to enzyme degradation was supported by the attenuated effect of pepsin and trypsin enzymes. Moreover, the bioconjugate posed no cytotoxicity to human cells and was also hemocompatible. Recent studies have shown the cellular uptake of the protein-coated carboxylate functionalized gold nanoparticles by human MG-63 osteosarcoma cells. ${ }^{66}$ Confocal microscopy and flow cytometry studies support the internalization of the nanoparticles. Both chemically reduced and green synthesized nanoparticles using zein, BSA, collagen, and lysozyme were shown to enter MG-63 cells (Figure 8B).

(A)

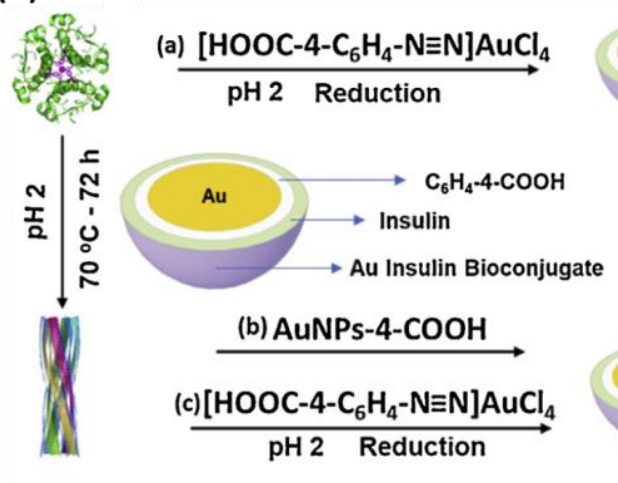

(B)

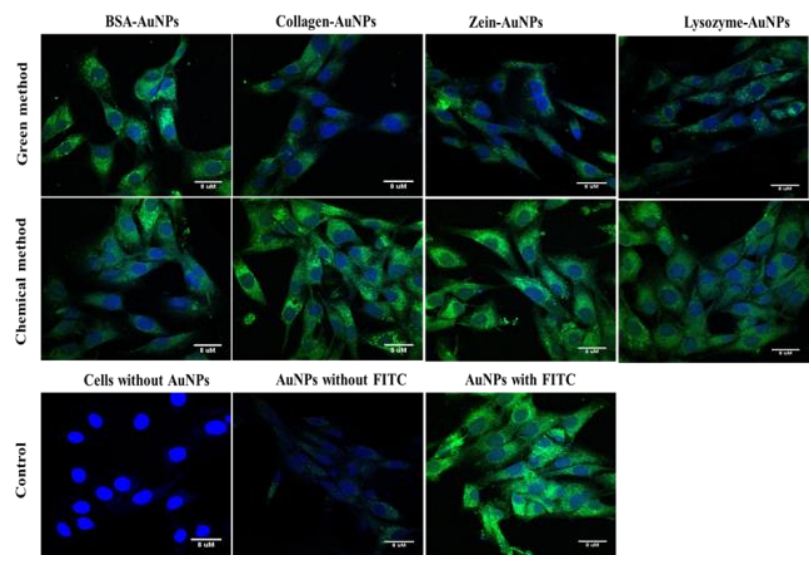

Figure 8. (A) Scheme showing different routes (a-d) for the fabrication of AuNPs-insulin bioconjugate and the dissociation of amyloid fibrils in the presence of gold-aryl nanoparticles. Reproduced with permission from ref 84. Copyright 2020, Elsevier. (B) Confocal microscopy images of the uptake of protein-coated gold-carbon nanoparticles synthesized using green and 
chemical reduction methods. The more intense the fluorescence the higher uptake of the AuNPs by MG-63 cells. The fluorescein isothiocyanate (FITC) probe-conjugated nanoparticles displayed green fluorescence while the nucleus stained with 4',6-Diamidino-2-phenylindole (DAPI) displayed blue fluorescence. Reproduced with permission from ref 66. Copyright 2020, American Chemical Society.

The modified gold NPs using diazonium salts were used also for the immobilization of DNA after encapsulation in cationic polyelectrolyte. ${ }^{85}$ These biomaterials can be used in nanomedicine with an emphasis on non-viral gene systems. Gel electrophoresis supports the interaction between the nanoparticles and DNA. Atomic force microscopy (AFM) was used to study the surface topography of the AuNPs-DNA bioconjugates stabilized with the biodegradable cationic polyelectrolyte, polydiallyldimethylammonium chloride (PDADMAC). Stabilization of DNA enhances the bioconjugates against DNase-I degradation. The measured heights of the unconjugated AuNPs from AFM measurements varied from 18-22 nm, whereas the height of PDADMAC-treated AuNPs increased to $30 \mathrm{~nm}$. The average height of DNA was found to be around $2.2 \mathrm{~nm}$, which increased to $30-35 \mathrm{~nm}$ after conjugation with AuNPs. The height of the AuNPs-PDADMAC-DNA conjugate increased significantly to $90 \mathrm{~nm} .{ }^{85}$

\section{DIAZONICS IN CATALYTIC AND ELECTROCATALYTIC NANOTECHNOLOGY}

Catalytic reduction of environmental pollutants such as nitrophenols is a vital contemporary topic for the prevention of environmental contamination. The Environmental Protection Agency listed nitrophenols as a top priority contaminant in nature. ${ }^{86} \mathrm{We}$ reported studies on the role of gold-carbon nanoparticles as a catalyst for the borohydride reduction of 4-nitrophenol (4-NPh) to

4-aminophenol (4-APh) ${ }^{28}$ Catalytic reduction of 4-NPh is typically modeled by the LangmuirHinshelwood model in which both borohydride and 4-NPh interact with the catalyst surface, followed by the reduction of 4-NPh to 4-APh and finally detachment of the product. A kinetic isotope effect suggests the possibility of aryl exchange with hydride on the surface of the 
catalyst. Stability experiments of the gold nanoparticles over several catalytic cycles indicate that the catalyst surface remains active and capable of the reduction of $92 \%$ of $4-\mathrm{NPh}$ even though considerable aggregation was measured using TEM. The favorable activation energy of 25 $\mathrm{kJ} / \mathrm{mol}$ is consistent with the enhanced catalytic activity on the surface of AuNPs. ${ }^{28}$ The catalytic study suggests that activation and restructuring of the catalyst surface rather than a diffusional barrier is responsible for an induction period at the beginning of the reaction.

Gold-aryl nanoparticles contributed to the progress of energy applications. ${ }^{87.88}$ Diazonium gold(III) salts were used as a unique source of zero-valent gold nanocomposites for electrochemical applications. Gold-carbon nanoparticles dispersed on bentonite surfaces for electrochemical hydrogen evolution pointed to a new horizon for diazonics in the preparation of low-cost, efficient, and stable electrocatalysts. ${ }^{89}$ Bentonite clay can be intercalated first with mercaptosilane to widen the interlayer spacing of the layered clay and then intercalated further with a perfluorinated diazonium gold(III) salt. Reduction of the diazonium salts provides gold nanoparticles tethered to the clay via aryl groups and thiols from mercaptosilane. The nanohybrid was used for electrocatalytic hydrogen production in hydrogen evolution reactions. ${ }^{89}$ The addition of gold enhanced the electrochemical hydrogen evolution with a noticeable high current density of $-25 \mathrm{~mA} \mathrm{~cm}^{-2}$ at $-1.0 \mathrm{~V}$ versus $\mathrm{Ag} / \mathrm{AgCl}$. The electrocatalytic properties of gold-aryl clay nanohybrids as efficient and robust catalysts show great potential in the sustainable energy sector.

\section{CONCLUSIONS}

The applications of diazonium chemistry for covalent surface modification results in a metalcarbon bond with putative robustness. Diazonics are preferred over non-diazonic processes due to the low reduction potential and ability to form organic layers with high surface coverage. 
Disadvantages in metal-thiolate interfaces originating from their decreased longevity under harsh conditions restrict their role in a wide range of applications, hence, the construction of robust metal-carbon interfaces has attracted great interest. Compiled data thus far and the exponential growth of experimental results will continue to spur on the great interest in diazonium salts as powerful surface modifiers.

Modified gold films allow the widespread applications as surface-enhanced optical spectroscopies, sensor technologies, and energy harvesting. Diazonium modification provides unique opportunities for the post-functionalization of organic functional groups and the design of gold surfaces with high selectivity. Developed approaches to the modification of gold films for the grafting of specific agents lead to the enhanced selectivity and sensitivity of the sensors via preconcentration of the analyte near the gold surface. Diazonium modification enables high loading/surface coverage of functional groups on the gold surface on plasmon-active thin films which is considered a perfect model for the detailed study of plasmon-induced chemical transformations.

The surge of applications of diazonics for modification of particles and surfaces in nanomedicine engineering has led to the development of substrates for proteins and drug stabilization and delivery. The outlook of significant advances using diazonics appears significant as diazonium cations react with nearly all types of metals, metal oxide, metalloid, and non-metal surfaces, and can be applied in energy, sensors, forensics, catalysis, and biomedical areas of research.

\section{AUTHOR INFORMATION}

\section{Corresponding Authors}

*Ahmed A. Mohamed (ah.mohamed@sharjah.ac.ae) 
*Alice E. Bruce (abruce@maine.edu)

\section{Notes}

The authors declare no financial interest.

\section{Biographies}

Mr. Ahmad A. L. Ahmad received his MS degree in 2011 from Jordan University of Science and Technology, Jordan. He was a lecturer in the Department of Chemistry at the University of Sharjah before starting his Ph.D. program at the University of Maine, USA in 2017, where he is co-advised by Professors Alice Bruce and Mitchell Bruce. Ahmad's research interests are focused on the synthesis and characterization of functionalized gold-aryl nanoparticles and their applications in catalysis, forensics, and environment.

Mr. Javad Parambath received his BSc (Hons) in chemistry from Hindu College, University of Delhi, India, in 2015 and MS in chemistry from Pondicherry Central University, India in 2018. He is currently a full-time research assistant in Dr. Ahmed Mohamed's laboratory, University of Sharjah, UAE. His current research focuses on the design and fabrication of organometallic gold nanoparticles and their nanocomposites for biomedical and energy applications.

Associate Professor Pavel S. Postnikov completed his Ph.D. degree in 2011 in organic chemistry with theoretical and practical insights in diazonium chemistry at the Tomsk Polytechnic University, Russian Federation. His research interests are in the preparation and reactivity of cationic organic species, especially hypervalent iodine compounds and diazonium salts as building blocks in organic synthesis. He is interested in the design of new functional materials using surface modification methods with active organic species.

Dr. Olga Guselnikova obtained her Ph.D. in 2019 from Tomsk Polytechnic University, Russian Federation and the University of Chemistry and Technology Prague, Czechia, and currently, she is a postdoctoral researcher at both universities. Her main scientific interests are surface modification using diazonium and iodonium salts, the design of SERS sensing, and new plasmon-assisted reactions for polymer science and organic chemistry. 
Dr. Mohamed M. Chehimi is a Senior Researcher at French CNRS. He received his Ph.D. in physical organic chemistry from Université Paris 7, France. His primary research fields are surface chemistry and XPS surface analysis, with a focus on developing diazonium salts as coupling agents in materials science and the design of reactive and functional polymer grafts and nanocomposites. He published over 350 research papers, 25 book chapters, and 3 patents to his credit and edited four books and six themed issues. He serves as Executive Editor-in-Chief of Chemistry Africa (Springer Nature).

Dr. Mitchell R. M. Bruce is a professor of chemistry at the University of Maine. He earned his Ph.D. in inorganic chemistry from Columbia University, NY, NY studying organometallic photochemistry followed by postdoctoral research at the University of North Carolina, Chapel Hill on the electrochemical activation of carbon dioxide. His research interests are focused on the mechanisms and redox reactions of metal sulfur complexes, metal-mediated thiolate-disulfide exchange, and gold nanoparticles for catalysis.

Dr. Alice E. Bruce is a professor of chemistry at the University of Maine. She earned her Ph.D. in inorganic chemistry from Columbia University, NY, NY studying metal-sulfur photochemistry followed by postdoctoral research at the University of North Carolina, Chapel Hill studying organometallic carbene and carbyne complexes. Her research interests are the medicinal chemistry of gold-based drugs, metal-mediated thiolate-disulfide exchange, metalsulfur redox chemistry, and gold nanoparticles for catalysis.

Dr. Ahmed A. Mohamed is an associate professor of chemistry at the University of Sharjah, UAE. He obtained his Ph.D. from the University of Maine on the mechanism of gold drugs under Professors Alice Bruce and Mitchell Bruce. He was a postdoctoral researcher at Texas A and M University under Professor John P. Fackler, Jr. His research interests are in gold chemistry including metal-based drugs and gold nanoparticles surface modification using diazonium salts for nanomedicine engineering.

\section{ACKNOWLEDGMENTS}

AAM acknowledges the University of Sharjah support of competitive grants 160-2142-029-P and 150-2142-017-P, Organometallic Research Group grant RISE-046-2016, and Functionalized 
Nanomaterials Synthesis Lab grant 151-0039. PSP and OG are thankful for the Tomsk Polytechnic University Competitiveness Enhancement Program.

\section{REFERENCES}

(1) Chehimi, M. M. (Ed.). Aryl Diazonium Salts: New Coupling Agents in Polymer and Surface Science; Wiley-VCH: Verlag GmbH \& Co. KGaA (2012).

(2) Harper, J. C.; Polsky, R.; Wheeler, D. R.; Brozik, S. M. Maleimide-Activated Aryl Diazonium Salts for Electrode Surface Functionalization with Biological and Redox-Active Molecules. Langmuir 2008, 24 (5), 2206-2211.

(3) Nguyen, V. Q.; Schaming, D.; Martin, P.; Lacroix, J. C. Nanostructured Mixed Layers of Organic Materials Obtained by Nanosphere Lithography and Electrochemical Reduction of Aryldiazonium Salts. Langmuir 2019, 35 (47), 15071-15077.

(4) Delamar, M.; Hitmi, R.; Pinson, J.; Savéant, J. Covalent Modification of Carbon Surfaces by Grafting of Functionalized Aryl Radicals Produced from Electrochemical Reduction of Diazonium Salts. J. Am. Chem. Soc. 1992, 114 (14), 5883-5884.

(5) Chira, A.; Bucur, B.; Radu, G. L. Electrodeposited Organic Layers Formed from Aryl Diazonium Salts for Inhibition of Copper Corrosion. Materials (Basel). 2017, 10 (3), 235.

(6) Sandomierski, M.; Voelkel, A. Diazonium Modification of Inorganic and Organic Fillers for the Design of Robust Composites: A Review. J. Inorg. Organomet. Polym. Mater. 2021, 31 (1), 1-21.

(7) Luo, P.; Ji, Z.; Li, C.; Shi, G. Aryl-Modified Graphene Quantum Dots with Enhanced Photoluminescence and Improved pH Tolerance. Nanoscale 2013, 5 (16), 7361-7367.

(8) Hai, X.; Feng, J.; Chen, X.; Wang, J. Tuning the Optical Properties of Graphene Quantum Dots for Biosensing and Bioimaging. J. Mater. Chem. B 2018, 6 (20), 3219-3234.

(9) Mo, F.; Qiu, D.; Wang, J. Recent Development of Aryl Diazonium Chemistry for the Derivatization of Aromatic Compounds. Chem. Rev. 2021, ASAP.

(10) Wu, T.; Fitchett, C. M.; Brooksby, P. A.; Downard, A. J. Building Tailored Interfaces through Covalent Coupling Reactions at Layers Grafted from Aryldiazonium Salts. ACS Appl. Mater. Interfaces 2021, 13 (10), 11545-11570. 
(11) Guo, L.; Ma, L.; Zhang, Y.; Cheng, X.; Xu, Y.; Wang, J.; Wang, E.; Peng, Z. Spectroscopic Identification of the Au-C Bond Formation upon Electroreduction of an Aryl Diazonium Salt on Gold. Langmuir 2016, 32 (44), 11514-11519.

(12) Laurentius, L.; Stoyanov, S. R.; Gusarov, S.; Kovalenko, A.; Du, R.; Lopinski, G. P.; McDermott, M. T. Diazonium-Derived Aryl Films on Gold Nanoparticles: Evidence for a Carbon-Gold Covalent Bond. ACS Nano 2011, 5 (5), 4219-4227.

(13) Allongue, P.; Delamar, M.; Desbat, B.; Fagebaume, O.; Hitmi, R.; Pinson, J.; Saveant, J.M. Covalent Modification of Carbon Surfaces by Aryl Radicals Generated from the Electrochemical Reduction of Diazonium Salts. J. Am. Chem. Soc. 1997, 119 (1), 201-207.

(14) Mohamed, A. A.; Salmi, Z.; Dahoumane, S. A.; Mekki, A.; Carbonnier, B.; Chehimi, M. M. Functionalization of Nanomaterials with Aryldiazonium Salts. Adv. Colloid Interface Sci. 2015, 225, 16-36.

(15) Shewchuk, D. M.; McDermott, M. T. Comparison of Diazonium Salt Derived and Thiol Derived Nitrobenzene Layers on Gold. Langmuir 2009, 25 (8), 4556-4563.

(16) Mahouche-Chergui, S.; Gam-Derouich, S.; Mangeney, C.; Chehimi, M. M. Aryl Diazonium Salts: A New Class of Coupling Agents for Bonding Polymers, Biomacromolecules and Nanoparticles to Surfaces. Chem. Soc. Rev. 2011, 40 (7), 4143-4166.

(17) Overton, A. T.; Mohamed, A. A. Gold(III) Diazonium Complexes for Electrochemical Reductive Grafting. Inorg. Chem. 2012, 51 (10), 5500-5502.

(18) Laforgue, A.; Addou, T.; Bélanger, D. Characterization of the Deposition of Organic Molecules at the Surface of Gold by the Electrochemical Reduction of Aryldiazonium Cations. Langmuir 2005, 21 (15), 6855-6865.

(19) Lo, M.; Diaw, A. K. D.; Gningue-Sall, D.; Aaron, J. J.; Oturan, M. A.; Chehimi, M. M. The Role of Diazonium Interface Chemistry in the Design of High Performance PolypyrroleCoated Flexible ITO Sensing Electrodes. Electrochem. Commun. 2017, 77, 14-18.

(20) Maldonado, S.; Smith, T. J.; Williams, R. D.; Morin, S.; Barton, E.; Stevenson, K. J. Surface Modification of Indium Tin Oxide via Electrochemical Reduction of Aryldiazonium Cations. Langmuir 2006, 22 (6), 2884-2891.

(21) Mesnage, A.; Lefèvre, X.; Jégou, P.; Deniau, G.; Palacin, S. Spontaneous Grafting of Diazonium Salts: Chemical Mechanism on Metallic Surfaces. Langmuir 2012, 28 (32), 1176711778. 
(22) Bakas, I.; Salmi, Z.; Gam-Derouich, S.; Jouini, M.; Lépinay, S.; Carbonnier, B.; Khlifi, A.; Kalfat, R.; Geneste, F.; Yagci, Y. Molecularly Imprinted Polymeric Sensings Layers Grafted from Aryl Diazonium-modified Surfaces for Electroanalytical Applications. A Mini Review. Surf. Interface Anal. 2014, 46 (10-11), 1014-1020.

(23) Mirkhalaf, F.; Graves, J. E. Nanostructured Electrocatalysts Immobilised on Electrode Surfaces and Organic Film Templates. Chem. Pap. 2012, 66 (5), 472-483.

(24) Cao, C.; Zhang, Y.; Jiang, C.; Qi, M.; Liu, G. Advances on Aryldiazonium Salt Chemistry Based Interfacial Fabrication for Sensing Applications. ACS Appl. Mater. Interfaces 2017, 9 (6), 5031-5049.

(25) Miyachi, M.; Yamamoto, Y.; Yamanoi, Y.; Minoda, A.; Oshima, S.; Kobori, Y.; Nishihara, H. Synthesis of Diazenido-Ligated Vanadium Nanoparticles. Langmuir 2013, 29 (17), 5099-5103.

(26) Neal, S. N.; Orefuwa, S. A.; Overton, A. T.; Staples, R. J.; Mohamed, A. A. Synthesis of Diazonium Tetrachloroaurate(III) Precursors for Surface Grafting. Inorganics 2013, 1 (1), 7084.

(27) Mohamed, A. A.; Neal, S. N.; Atallah, B.; AlBab, N. D.; Alawadhi, H. A.; Pajouhafsar, Y.; Abdou, H. E.; Workie, B.; Sahle-Demessie, E.; Han, C.; Monge, M.; Lopez-de-Luzuriaga, J. M.; Reibenspies, J. H.; Chehimi, M. M. Synthesis of Gold Organometallics at the Nanoscale. J. Organomet. Chem. 2018, 877, 1-11.

(28) Ahmad, A. A. L.; Panicker, S.; Chehimi, M. M.; Monge, M.; Lopez-De-Luzuriaga, J. M.; Mohamed, A. A.; Bruce, A. E.; Bruce, M. R. M. Synthesis of Water-Soluble Gold-Aryl Nanoparticles with Distinct Catalytic Performance in the Reduction of the Environmental Pollutant 4-Nitrophenol. Catal. Sci. Technol. 2019, 9 (21), 6059-6071.

(29) Panicker, S.; Marcano, A.; Isah, S.; Kenney, B.; Workie, B.; Han, C.; Lee, H.; Chehimi, M. M.; Mohamed, A. A. Organometallic Gold Nanoparticles and Thin Films from Cis-and Trans-Tetrazonium Gold (III) Salts for Electrochemical and Photothermal Mirror Properties. J. Organomet. Chem. 2021, 935, 121681.

(30) Orefuwa, S. A.; Ravanbakhsh, M.; Neal, S. N.; King, J. B.; Mohamed, A. A. Robust Organometallic Gold Nanoparticles. Organometallics, 2014, 33, 439-442. 
(31) Neal, S. N.; Workie, B.; McCandless, B.; Mohamed, A. A. Gold Organic Thin Films from the Reductive Grafting of Diazonium Gold(III) Salts. J. Electroanal. Chem. 2015, 757, 7379.

(32) Gervais, E.; Aceta, Y.; Gros, P.; Evrard, D. Study of an AuNPs Functionalized Electrode Using Different Diazonium Salts for the Ultra-Fast Detection of $\mathrm{Hg}(\mathrm{II})$ Traces in Water. Electrochimica Acta 2018, 261, 346-355.

(33) Du, J.; Du, H.; Li, X.; Fan, J.; Peng, X. In-Situ Colorimetric Recognition of Arylamine Based on Chemodosimeter-Functionalized Gold Nanoparticle. Sens. Actuators B Chem. 2017, $248,318-323$.

(34) Razzaq, H.; Qureshi, R.; Cabo-Fernandez, L.; Schiffrin, D. J. Synthesis of Au ClustersRedox Centre Hybrids by Diazonium Chemistry Employing Double Layer Charged Gold Nanoparticles. J. Electroanal. Chem. 2018, 819, 9-15.

(35) Troian-Gautier, L.; Valkenier, H.; Mattiuzzi, A.; Jabin, I.; Brande, N. V. D.; Mele, B. V.; Hubert, J.; Reniers, F.; Bruylants, G.; Lagrost, C.; Leroux, Y. Extremely Robust and PostFunctionalizable Gold Nanoparticles Coated with Calix[4]Arenes via Metal-Carbon Bonds. Chem Comm. 2016, 52 (69), 10493-10496.

(36) Nguyen, M.; Kherbouche, I.; Gam-Derouich, S.; Ragheb, I.; Lau-Truong, S.; Lamouri, A.; Lévi, G.; Aubard, J.; Decorse, P.; Félidj, N.; Mangeney, C. Regioselective Surface Functionalization of Lithographically Designed Gold Nanorods by Plasmon-Mediated Reduction of Aryl Diazonium Salts. Chem. Commun. 2017, 53 (82), 11364-11367.

(37) Perezjuste, J.; Pastorizasantos, I.; Lizmarzan, L.; Mulvaney, P. Gold Nanorods: Synthesis, Characterization and Applications. Coord. Chem. Rev 2005, 249 (17-18), 1870-1901.

(38) Scarabelli, L.; Sánchez-Iglesias, A.; Pérez-Juste, J.; Liz-Marzán, L. M. A “Tips and Tricks" Practical Guide to the Synthesis of Gold Nanorods. J. Phys. Chem. Lett. 2015, 6 (21), $4270-4279$.

(39) Ahmad, R.; Boubekeur-Lecaque, L.; Nguyen, M.; Lau-Truong, S.; Lamouri, A.; Decorse, P.; Galtayries, A.; Pinson, J.; Felidj, N.; Mangeney, C. Tailoring the Surface Chemistry of Gold Nanorods through $\mathrm{Au}-\mathrm{C} / \mathrm{Ag}-\mathrm{C}$ Covalent Bonds Using Aryl Diazonium Salts. J. Phys. Chem. C 2014, 118 (33), 19098-19105.

(40) Jasmin, J. P.; Miserque, F.; Dumas, E.; Vickridge, I.; Ganem, J. J.; Cannizzo, C.; Chaussé, A. XPS and NRA Investigations during the Fabrication of Gold Nanostructured 
Functionalized Screen-Printed Sensors for the Detection of Metallic Pollutants. Applied Surface Science 2017, 397, 159-166.

(41) Ait-Touchente, Z.; Falah, S.; Scavetta, E.; Chehimi, M. M.; Touzani, R.; Tonelli, D.; Taleb, A. Different Electrochemical Sensor Designs Based on Diazonium Salts and Gold Nanoparticles for Pico Molar Detection of Metals. Molecules 2020, 25 (17), 3903.

(42) Guselnikova, O.; Postnikov, P.; Erzina, M.; Kalachyova, Y.; Švorčík, V.; Lyutakov, O. Pretreatment-Free Selective and Reproducible SERS-Based Detection of Heavy Metal Ions on DTPA Functionalized Plasmonic Platform. Sensors Actuators B Chem. 2017, 253, 830-838.

(43) Guselnikova, O.; Dvorankova, B.; Kakisheva, K.; Kalachyova, Y.; Postnikov, P.; Svorcik, V.; Lyutakov, O. Rapid SERS-Based Recognition of Cell Secretome on the Folic AcidFunctionalized Gold Gratings. Anal. Bioanal. Chem. 2019, 411 (15), 3309-3319.

(44) Guselnikova, O.; Kalachyova, Y.; Hrobonova, K.; Trusova, M.; Barek, J.; Postnikov, P.; Svorcik, V.; Lyutakov, O. SERS Platform for Detection of Lipids and Disease Markers Prepared Using Modification of Plasmonic-Active Gold Gratings by Lipophilic Moieties. Sensors Actuators B Chem. 2018, 265, 182-192.

(45) Miliutina, E.; Guselnikova, O.; Kushnarenko, A.; Bainova, P.; Postnikov, P.; Hnatowicz, V.; Svorcik, V.; Lyutakov, O. Single Plasmon-Active Optical Fiber Probe for Instantaneous Chiral Detection. ACS Sensors 2020, 5 (1), 50-56.

(46) Miliutina, E.; Guselnikova, O.; Burtsev, V.; Elashnikov, R.; Postnikov, P.; Svorcik, V.; Lyutakov, O. Plasmon-Active Optical Fiber Functionalized by Metal Organic Framework for Pesticide Detection. Talanta 2020, 208, 120480.

(47) Miliutina, E.; Guselnikova, O.; Chufistova, S.; Kolska, Z.; Elashnikov, R.; Burtsev, V.; Postnikov, P.; Svorcik, V.; Lyutakov, O. Fast and All-Optical Hydrogen Sensor Based on GoldCoated Optical Fiber Functionalized with Metal-Organic Framework Layer. ACS Sensors 2019, 4 (12), 3133-3140.

(48) Guselnikova, O.; Postnikov, P.; Elashnikov, R.; Trusova, M.; Kalachyova, Y.; Libansky, M.; Barek, J.; Kolska, Z.; Švorčík, V.; Lyutakov, O. Surface Modification of Au and Ag Plasmonic Thin Films via Diazonium Chemistry: Evaluation of Structure and Properties. Colloids Surfaces A Physicochem. Eng. Asp. 2017, 516, 274-285. 
Kesavan, S.; Abraham John, S. Spontaneous Grafting: A Novel Approach to Graft Diazonium Cations on Gold Nanoparticles in Aqueous Medium and Their Self-Assembly on Electrodes. J. Colloid Interface Sci. 2014, 428, 84-94.

(50) Nguyen, M.; Sun, X.; Lacaze, E.; Winkler, P. M.; Hohenau, A.; Krenn, J. R.; Bourdillon, C.; Lamouri, A.; Grand, J.; Lévi, G.; Boubekeuer-Lecaque, L. ; Mangeney, C. ; Felidj, N. Engineering Thermoswitchable Lithographic Hybrid Gold Nanorods as Plasmonic Devices for Sensing and Active Plasmonics Applications. ACS Photonics 2015, 2 (8), 1199-1208.

(51) Hetemi, D.; Noël, V.; Pinson, J. Grafting of Diazonium Salts on Surfaces: Application to Biosensors. Biosensors 2020, 10 (1), 4.

(52) Pinson, J.; Podvorica, F. Attachment of Organic Layers to Conductive or Semiconductive Surfaces by Reduction of Diazonium Salts. Chem. Soc. Rev. 2005, 34 (5), 429-439.

(53) Guselnikova, O.; Postnikov, P.; Kalachyova, Y.; Kolska, Z.; Libansky, M.; Zima, J.; Svorcik, V.; Lyutakov, O. Large-Scale, Ultrasensitive, Highly Reproducible and Reusable Smart SERS Platform Based on PNIPAm-Grafted Gold Grating. ChemNanoMat 2017, 3 (2), 135-144.

(54) Guselnikova, O.; Postnikov, P.; Elashnikov, R.; Miliutina, E.; Svorcik, V.; Lyutakov, O. Metal-Organic Framework (MOF-5) Coated SERS Active Gold Gratings: A Platform for the Selective Detection of Organic Contaminants in Soil. Anal. Chim. Acta 2019, 1068, 70-79.

(55) Guselnikova, O.; Postnikov, P.; Trelin, A.; Švorčík, V.; Lyutakov, O. Dual Mode Chip Enantioselective Express Discrimination of Chiral Amines via Wettability-Based Mobile Application and Portable Surface-Enhanced Raman Spectroscopy Measurements. ACS Sensors 2019, 4 (4), 1032-1039.

(56) Guselnikova, O.; Marque, S. R. A.; Tretyakov, E. V; Mares, D.; Jerabek, V.; Audran, G.; Joly, J.-P.; Trusova, M.; Svorcik, V.; Lyutakov, O.; Postnikov, P. Unprecedented PlasmonInduced Nitroxide-Mediated Polymerization (PI-NMP): A Method for Preparation of Functional Surfaces. J. Mater. Chem. A 2019, 7 (20), 12414-12419.

(57) Fan, L.; Wang, G.; Liang, W.; Yan, W.; Guo, Y.; Shuang, S.; Dong, C.; Bi, Y. Label-Free and Highly Selective Electrochemical Aptasensor for Detection of PCBs Based on Nickel Hexacyanoferrate Nanoparticles/Reduced Graphene Oxides Hybrids. Biosens. Bioelectron. 2019, $145,111728$.

(58) Guselnikova, O.; Trelin, A.; Miliutina, E.; Elashnikov, R.; Sajdl, P.; Postnikov, P.; Kolska, Z.; Svorcik, V.; Lyutakov, O. Plasmon-Induced Water Splitting through Flexible Hybrid 
2D Architecture up to Hydrogen from Seawater under NIR Light. ACS Appl. Mater. Interfaces 2020, 12 (25), 28110-28119.

(59) Pichereau, L.; López, I.; Cesbron, M.; Dabos-Seignon, S.; Gautier, C.; Breton, T. Controlled Diazonium Electrografting Driven by Overpotential Reduction: A General Strategy to Prepare Ultrathin Layers. Chem. Commun. 2019, 55 (4), 455-457.

(60) Meng, X.; Liu, L.; Ouyang, S.; Xu, H.; Wang, D.; Zhao, N.; Ye, J. Nanometals for Solarto-Chemical Energy Conversion: from Semiconductor-Based Photocatalysis to PlasmonMediated Photocatalysis and Photo-Thermocatalysis. Adv. Mater. 2016, 28 (32), 6781-6803.

(61) Guselnikova, O.; Olshtrem, A.; Kalachyova, Y.; Panov, I.; Postnikov, P.; Svorcik, V.; Lyutakov, O. Plasmon Catalysis on Bimetallic Surface Selective Hydrogenation of Alkynes to Alkanes or Alkenes. J. Phys. Chem. C 2018, 122 (46), 26613-26622.

(62) Guselnikova, O.; Postnikov, P.; Chehimi, M. M.; Kalachyovaa, Y.; Svorcik, V.; Lyutakov, O. Surface Plasmon-Polariton: A Novel Way to Initiate Azide-Alkyne Cycloaddition. Langmuir 2019, 35 (6), 2023-2032.

(63) Erzina, M.; Guselnikova, O.; Postnikov, P.; Elashnikov, R.; Kolska, Z.; Miliutina, E.; Švorčík, V.; Lyutakov, O. Plasmon-Polariton Induced, “from Surface” RAFT Polymerization, as a Way toward Creation of Grafted Polymer Films with Thickness Precisely Controlled by SelfLimiting Mechanism. Adv. Mater. Interfaces 2018, 5 (22), 1801042.

(64) AlMashrea, B. A.; Abla, F.; Chehimi, M. M.; Workie, B.; Han, C.; Mohamed, A. A. Polyaniline Coated Gold-Aryl Nanoparticles: Electrochemical Synthesis and Efficiency in Methylene Blue Dye Removal. Synth. Met. 2020, 269, 116528.

(65) Fernandez-Bravo, A.; Sivakumar, P.; Melikechi, N.; Mohamed, A. A. Femtosecond Laser Ablation Synthesis of Aryl Functional Group Substituted Gold Nanoparticles. J. Nanosci. Nanotechnol. 2017, 17 (4), 2852-2856.

(66) Hameed, M.; Panicker, S.; Abdallah, S. H.; Khan, A. A.; Han, C.; Chehimi, M. M.; Mohamed, A. A. Protein-Coated Aryl Modified Gold Nanoparticles for Cellular Uptake Study by Osteosarcoma Cancer Cells. Langmuir 2020, 36 (40), 11765-11775.

(67) Ahmady, I. M.; Hameed, M. K.; Almehdi, A. M.; Arooj, M.; Workie, B.; SahleDemessie, E.; Han, C.; Mohamed, A. A. Green and Cytocompatible Carboxyl Modified GoldLysozyme Nanoantibacterial for Combating Multidrug-Resistant Superbugs. Biomater. Sci. 2019, 7 (12), 5016-5026. 
(68) Ahmed, M. K.; El-Naggar, M. E.; Aldalbahi, A.; El-Newehy, H. M.; Menazea, A. A. Methylene Blue Degradation under Visible Light of Metallic Nanoparticles Scattered into Graphene Oxide using Laser Ablation Technique in Aqueous Solutions. J. Mol. Liquids 2020, $315,113794$.

(69) Zakria, M. A.; Menazea, A. A.; Mostafa, A. M.; Al-Ashkar, E. A. Ultra-Thin Silver Nanoparticles Film Prepared via Pulsed Laser deposition: Synthesis, Characterization, and its Catalytic Activity on Reduction of 4-Nitrophenol. Surf. Interfaces 2020, 19, 100438.

(70) Panicker, S.; Ahmady, I. M.; Han, C.; Chehimi, M.; Mohamed, A. A. On Demand Release of Ionic Silver from Gold-Silver Alloy Nanoparticles: Fundamental Antibacterial Mechanisms Study. Mater. Today Chem. 2020, 16, 100237.

(71) Colino, C. I.; Lanao, J. M.; Gutierrez-Millan, C. Recent Advances in Functionalized Nanomaterials for the Diagnosis and Treatment of Bacterial Infections. Mater. Sci. Eng. C 2021, $121,111843$.

(72) Al-Zubeidi, A.; Stein, F.; Flatebo, C.; Rehbock, C.; Jebeli, S. A.; Landes, C. F.; Barcikowski, S.; Link, S. Single-Particle Hyperspectral Imaging Reveals Kinetics of Silver Ion Leaching from Alloy Nanoparticles. ACS Nano 2021, 15, 8363-8375.

(73) Chaudhuri, R. G.; Paria, S. Core/Shell Nanoparticles: Classes, Properties, Synthesis Mechanisms, Characterization, and Applications, Chem. Rev. 2011, 112, 2373-2433.

(74) Zhang, Q.; Lee, I.; Joo, J. B.; Zaera, F.; Yin, Y. Core-Shell Nanostructured Catalysts, Acc. Chem. Res. 2012, 46, 1816-1824.

(75) Abla, F.; Kanan, S. M.; Park, Y.; Han, C.; Omastova, M.; Chehimi, M. M.; Mohamed, A. A. Exceptionally Redox-Active Precursors in the Synthesis of Gold Core-Tin Oxide Shell Nanostructures. Colloids Surfaces A Physicochem. Eng. Asp. 2021, 616, 126266.

(76) Nelson, D. F.; Kirk, P. L. The Identification of Saliva, J. Forensic Med. 1963, 10, 14-21.

(77) Stone, D. B. Diazonium Salts as Spot Test and Synthetic Reagents, J. Chem. Edu. 1971, $48,413-414$.

(78) Jenkins, T. F.; Walsh, M. E. Explosives Development of Field Screening Methods for TNT, 2,4-DNT and RDX in Soil, Talanta 1992, 39, 419-428.

(79) Ahmad, A. A. L.; Alawadhi, A. H.; Park, J.; Abdou, H. E.; Mohamed, A. A. Evaluation of Diazonium Gold (III) Salts in Forensic Chemistry: Latent Fingerprint Development on Metal Surfaces. Forensic Chem. 2019, 13, 100144. 
(80) Almheiri, S.; Ahmad, A. A. L.; Le Droumaguet, B.; Pires, R.; Mohamed, A. A.; Chehimi, M. M. Development of Latent Fingerprints via Aryldiazonium Tetrachloroaurate Salts on Copper Surfaces: An XPS Study. Langmuir 2020, 36 (1), 74-83.

(81) Retout, M.; Blond, P.; Jabin, I.; Bruylants. G. Ultrastable PEGylated Calixarene-Coated Gold Nanoparticles with a Tunable Bioconjugation Density for Biosensing Applications. Bioconjugate Chem. 2021, 32, 290-300.

(82) Adjei, I. M.; Sharma, B.; Labhasetwar, V. Nanoparticles: Cellular Uptake and Cytotoxicity. Adv Exp Med Biol. 2014, 811, 73-91.

(83) He, G.; Huang, P.; Chen, X. Theranostic Multimodal Gold Nanoclusters. Nat. Biomed. Eng. 2020, 4, 668-669.

(84) AlBab, N. D.; Hameed, M. K.; Maresova, A.; Ahmady, I. M.; Arooj, M.; Han, C.; Workie, B.; Chehimi, M.; Mohamed, A. A. Inhibition of Amyloid Fibrillation, Enzymatic Degradation and Cytotoxicity of Insulin at Carboxyl Tailored Gold-Aryl Nanoparticles Surface. Colloids Surfaces A Physicochem. Eng. Asp. 2020, 586, 124279.

(85) Panicker, S.; Ahmady, I. M.; Almehdi, A. M.; Workie, B.; Sahle-Demessie, E.; Han, C.; Chehimi, M. M.; Mohamed, A. A. Gold-Aryl Nanoparticles Coated with Polyelectrolytes for Adsorption and Protection of DNA against Nuclease Degradation. Appl. Organomet. Chem. 2019, 33 (4), e4803.

(86) US Environmental Protection Agency. 1976. Water Quality Criteria. Washington, DC: US Environmental Protection Agency.

(87) Mirkhalaf, F.; Schiffrin, D. J. Electrocatalytic Oxygen Reduction on Functionalized Gold Nanoparticles Incorporated in a Hydrophobic Environment. Langmuir 2010, 26, 18, 1499515001 .

(88) Lenne, Q.; Mattiuzzi, A.; Jabin, I.; Le Poul, N.; Leroux, Y. R.; Lagrost, C. Functionalizing Gold Nanoparticles with Calix[4]arenes Monolayers for Enhancing Selectivity and Stability in ORR Electrocatalysis. Adv. Mater. Interfaces 2020, 2001557.

(89) Jlassi, K.; Zavahir, S.; Kasak, P.; Krupa, I.; Mohamed, A. A.; Chehimi, M. M. Emerging Clay-Aryl-Gold Nanohybrids for Efficient Electrocatalytic Proton Reduction. Energy Convers. Manag. 2018, 168, 170-177. 
TOC

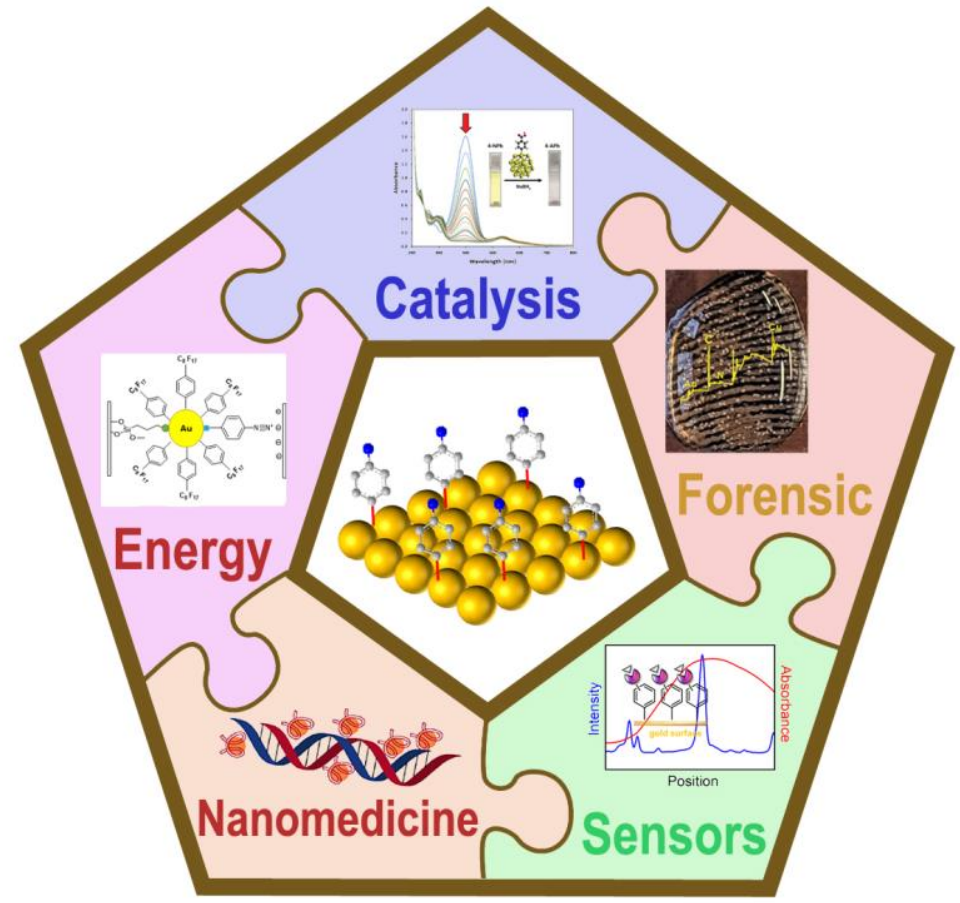

